\title{
P87 - A national multicenter registration of treatment with omalizumab in Danish asthmatic children
}

Katrine B Spangenberg*, Inger Merete Jørgensen, Susanne Halken, Lone Agertoft, Frederik Buchwald, Sune Rubak, Margrethe Friberg, Henrik Fomsgaard Kjær, Thomas Petersen Houmann, Thomas Kongstad

From 3rd Pediatric Allergy and Asthma Meeting (PAAM)

Athens, Greece. 17-19 October 2013

\section{Background}

In Denmark, Omalizumab is approved for treating children with severe persistent allergic asthma older than 6 years of age. No systematic registration of the efficacy in the Danish child population according to asthma symptoms or the efficacy on co-morbid allergic symptoms exists. A broad panel of outcome measures is necessary to evaluate the efficacy of Omalizumab treatment.

\section{Aim}

To provide a standardized systematic registration in order to create a database enrolling children with severe allergic asthma treated with Omalizumab.

\section{Method and study design}

A national multicenter registration and follow-up study based on children with clinical persistent severe allergic asthma including both retrospective and prospective registration.

\section{Inclusion criteria}

Children, 6-18 years of age, with severe persistent allergic asthma according to GINA treated with Omalizumab.

\section{Outcome registration}

A broad panel of outcome measures is scheduled at baseline and during treatment:
- Lung function

- ACT score

- Peak-flow

- FeNO

- Mannitol/Methacholin test

- Skin prick-test

- Quality of life score. (Juniper)

- Rhinitis score, R-RTSS

- SCORAD score

The monitoring plan and follow-up programme will be presented in a flowchart.

\section{Conclusion}

We believe that a national systematic registration will increase knowledge regarding efficacy of Omalizumab treatment in this rare group of severe allergic asthmatic children.

Published: 28 February 2014

Outcome

- Asthma exacerbations

- Hospitalizations

- Medication

Pediatric Department, Hillerød University Hospital, Denmark 